\title{
Seymour Fracture in a Pediatric Patient: A Case Report
}

\author{
Sumedha Bandi ${ }^{1}$, Emily Drone ${ }^{2}$, Ariel Vera ${ }^{2}$, Latha Ganti ${ }^{2,3,4}$ \\ 1. Emergency Medicine, University of Minnesota, Minneapolis, USA 2. Emergency Medicine, University of Central \\ Florida/HCA Healthcare Osceola Regional Medical Center, Orlando, USA 3. Emergency Medicine, Envision Physician \\ Services, Nashville, USA 4. Emergency Medical Services, Polk County Fire Rescue, Bartow, USA
}

Corresponding author: Latha Ganti, latha.ganti@ucf.edu

\begin{abstract}
In this report, the authors present the case of a child who sustained a specific type of mallet finger injury known as a Seymour fracture. This is an important injury to recognize in the emergency department as it is associated with significant morbidity if not treated appropriately. This is especially of concern in children, where the tissue can get trapped in the growth plate. Children also face a high risk of deformity due to growth arrest. Management includes thorough washout, reduction of displacement, and antibiotics and tetanus prophylaxis if there is an open fracture.
\end{abstract}

Categories: Emergency Medicine, Pediatrics

Keywords: seymour fracture, mallet injury

\section{Introduction}

Pediatric hand fractures make up 2.3\% of all ED visits [1]; these are more common in boys [2], with the most common mechanism being those secondary to sports-related activities. Phalangeal fractures are most common in the 9-12-year age group, and the most commonly affected finger is the middle finger [1].

A mallet finger injury is one of the most common injuries and is frequently associated with sport-related activities. One specific type of mallet finger injury, the Seymour fracture, results from a juxta epiphyseal fracture on the distal phalanx of the finger [1]. This injury involves avulsion of the nail and is usually classified as a Salter-Harris grade I or II fracture.

Early evaluation and appropriate treatment of a Seymour fracture include the administration of tetanus and antibiotic prophylaxis, and prompt orthopedic consultation [3]. Seymour fractures can reliably be identified with a good lateral X-ray and a high degree of suspicion.

Review began 09/18/2020 Review ended 09/26/2020 Published 09/27/2020

() Copyright 2020

Bandi et al. This is an open access article distributed under the terms of the Creative Commons Attribution License CC-BY 4.0., which permits unrestricted use, distribution, and reproduction in any medium, provided the original author and source are credited.

\section{Case Presentation}

A school-aged boy presented to the emergency department after catching his middle finger of his left hand in a hoverboard, which had caused avulsion of the distal phalanx through the skin. The bone was seen protruding through the bleeding, injured nailbed (Figure 1). 


\section{Cureus}

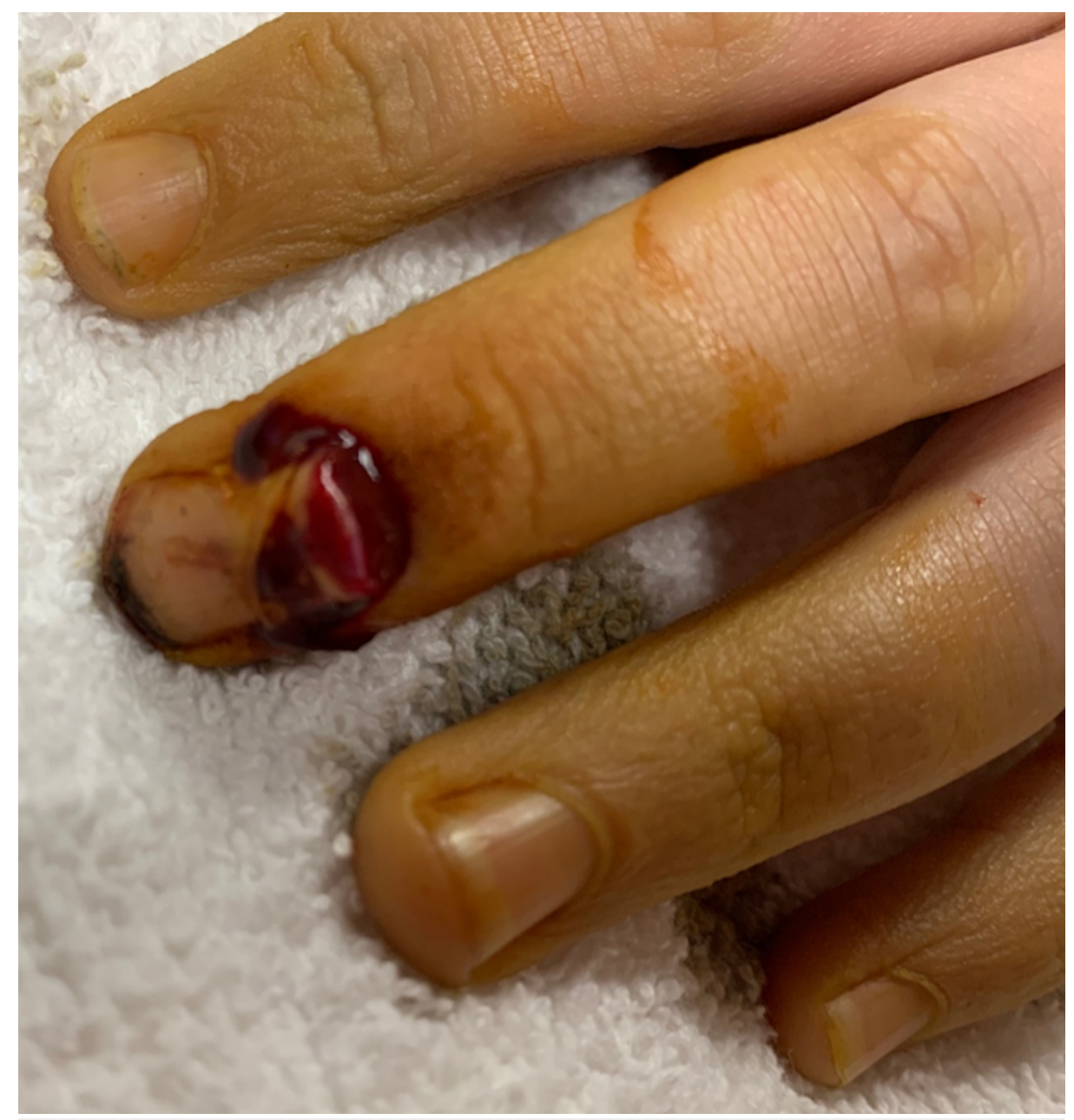

FIGURE 1: Photograph showing avulsion of the distal phalanx through the skin

His vital signs included temperature of $98.1^{\circ} \mathrm{F}$, pulse of 98 beats per minute, respiratory rate of 16 breaths per minute, blood pressure of $117 / 73 \mathrm{mmHg}$, and oxygen saturation at $100 \%$ on room air. Physical examination revealed nail avulsion and ecchymosis. The sensation in the hand was intact. The radial pulse was also intact. The range of motion of the other fingers was also found to be intact. No laboratory studies were obtained. Radiographs demonstrated a severely displaced fracture through the epiphyseal plate of the base of the distal phalanx with a marked transverse displacement of the distal phalanx, with small soft tissue gas noted at the fracture site (Figure 2). 


\section{Cureus}

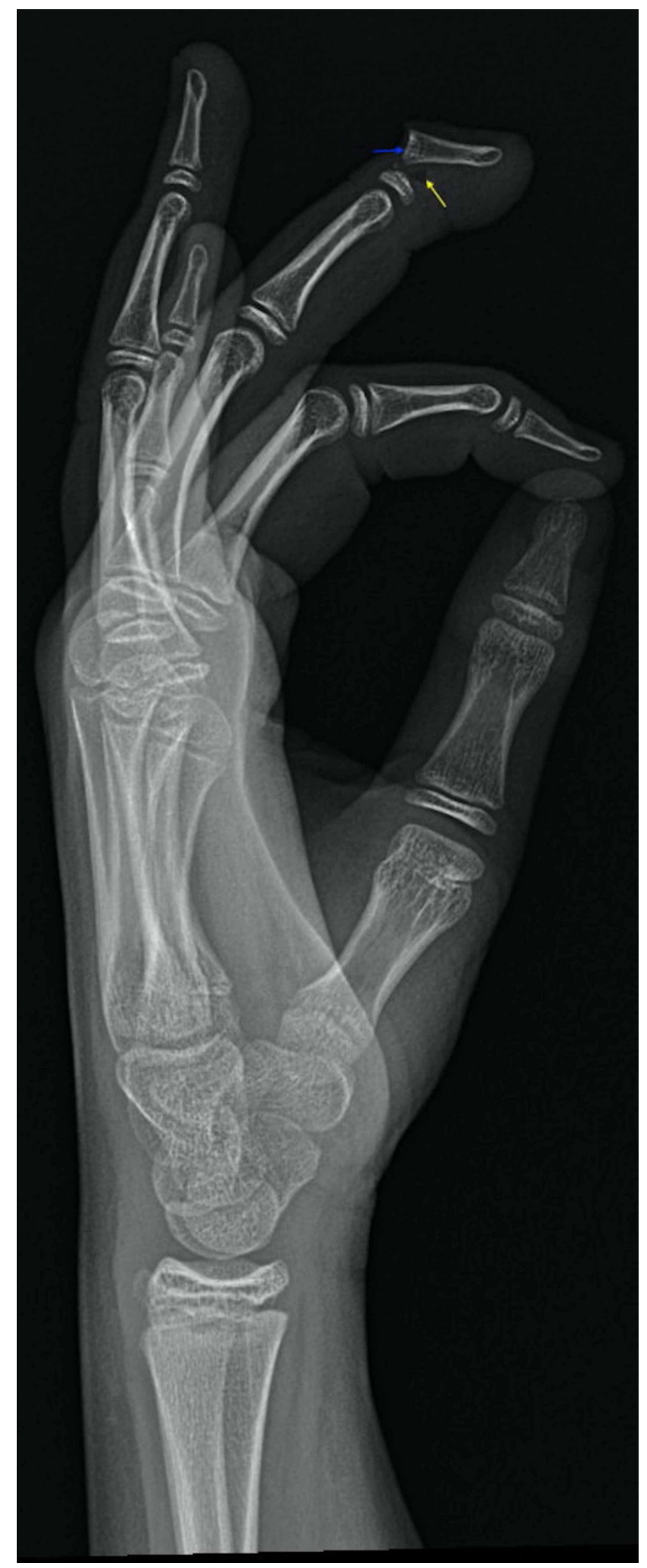

FIGURE 2: Radiograph marked transverse displacement of the distal phalanx (blue arrow), with small soft tissue gas noted at the fracture site (yellow arrow)

The wound was thoroughly irrigated with $250 \mathrm{ml}$ of normal saline. No evidence of a foreign body was found. The patient's tetanus status was up to date; he was given a weight-based dose of liquid ibuprofen for analgesia and one gram of cefazolin for the open fracture. The patient was transferred to the hand surgeon at the local children's hospital due to the degree of displacement and the need for a thorough washout and closed reduction of the fracture.

\section{Discussion}

A Seymour fracture can easily be overlooked as a minor injury to the nail. The nail bed laceration itself is usually not visible, but the proximal edge of the nail plate sits on top of the eponychial fold rather than 
beneath, making the nail appear "too long" in comparison to the other nails [1].

The pathophysiology, being similar to that of a mallet injury in adults, most commonly involves crushing injuries, sports injuries, and falls. This injury typically occurs when the distal phalanx of a fully extended digit undergoes forceful flexion, or when the distal phalanx experiences a crush injury [3]. Early evaluation and treatment have been the most effective in minimizing the risk of infection and any other complications [4]. It is important to consult orthopedics or a hand specialist, especially with pediatric patients. Open injuries may warrant operative intervention given that they are more prone to soft tissue infection and development of osteomyelitis [3]. Injury-related complications include osteomyelitis, distal phalanx growth disturbance, flexion deformity, and nail deformity [5]. Treatment-related complications like a secondary fracture displacement are uncommon but have been reported [6]. However, the majority of patients have good clinical outcomes.

Treatment for a Seymour fracture is dependent on whether it is an open or closed fracture. In the case of an open fracture that is prone to infection, it should be treated with operative irrigation, debridement, and intravenous antibiotics, along with a careful exploration to remove the proximal nail plate from the site of incarceration [5-6]. In closed fractures with severe soft tissue damage including the nail fold, the use of antibiotics is recommended [5]. Whenever possible, the nail should not be removed. The nail stabilizes the fracture, and the removal could make the injury more troublesome [6]. Interposed tissue should be removed from the fracture line. Late presentations of Seymour fracture often result in infection, growth arrest, and persistent mallet deformity of the distal phalanx [6].

\section{Conclusions}

Seymour fractures are rare and often underestimated injuries that require early treatment. This case presentation highlights the common features of a Seymour fracture. The common pitfalls associated with this fracture are as follows: 1) clinicians tend to minimize workup in pediatric patients and 2) proximal nail injury can look deceptively benign.

\section{Additional Information \\ Disclosures}

Human subjects: Consent was obtained by all participants in this study. HCA Centralized Algorithms for Research Rules on IRB Exemptions (CARRIE)/IRB manager issued approval 2020-482. HCA Centralized Algorithms for Research Rules on IRB Exemptions (CARRIE)/ IRB manager issued approval 2020-482. Based on the information provided and attested as true, the research plan described does not require IRB oversight. This is because you are either a) not engaging in research with human subjects as defined by federal regulations; b) engaging in research with human subjects deemed excluded from IRB oversight per 45CFR46.102(1) OR c) engaging in research with sufficient human subject protections in the design to meet one or more IRB exemption criteria set forth in 45CFR46.104. Conflicts of interest: In compliance with the ICMJE uniform disclosure form, all authors declare the following: Payment/services info: All authors have declared that no financial support was received from any organization for the submitted work. Financial relationships: All authors have declared that they have no financial relationships at present or within the previous three years with any organizations that might have an interest in the submitted work. Other relationships: All authors have declared that there are no other relationships or activities that could appear to have influenced the submitted work.

\section{Acknowledgements}

This research was supported (in whole or in part) by HCA Healthcare and/or an HCA Healthcare affiliated entity. The views expressed in this publication represent those of the author(s) and do not necessarily represent the official views of HCA Healthcare or any of its affiliated entities.

\section{References}

1. Nellans KW, Chung KC: Pediatric hand fractures. Hand Clin. 2013, 29:569-578. 10.1016/j.hcl.2013.08.009

2. Chew EM, Chong AK: Hand fractures in children: epidemiology and misdiagnosis in a tertiary referral hospital. J Hand Surg Am. 2012, 37:1684-1688. 10.1016/j.jhsa.2012.05.010

3. Abzug JM, Kozin SH: Seymour fractures. J Hand Surg Am. 2013, 38:2267-2270. 10.1016/j.jhsa.2013.08.104

4. Samade R, Lin JS, Popp JE, Samora JB: Delayed presentation of Seymour fractures: a single institution experience and management recommendations (Epub ahead of print). Hand (N Y). 2019, $10.1177 / 1558944719878846$

5. Liao JCY, Chong AK: Pediatric hand and wrist fractures . Clin Plast Surg. 2019, 46:425-436. 10.1016/i.cps.2019.02.012

6. Krusche-Mandl I, Köttstorfer J, Thalhammer G, Aldrian S, Erhart J, Platzer P: Seymour fractures: retrospective analysis and therapeutic considerations. J Hand Surg Am. 2013, 38:258-264. 10.1016/j.jhsa.2012.11.015 